\title{
Spontaneous dislocation of the endocardial lead into the left ventricle through the intraventricular septum
}

\author{
Samoistne przemieszczenie elektrody endokawitarnej do światła lewej komory \\ poprzez przegrodę międzykomorową
}

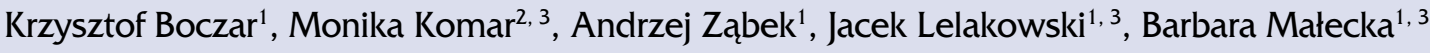 \\ 'Department of Electrocardiology, John Paul II Hospital in Krakow, Krakow, Poland \\ 2Department of Cardiac and Vascular Diseases, John Paul II Hospital in Krakow, Krakow, Poland \\ ${ }^{3}$ Institute of Cardiology, Jagiellonian University Medical College, Krakow, Poland
}

We report a case of a 66-year-old woman with a history of DDD pacemaker implantation in 2005 due to vasovagal syncope and generator change in 2014. The patient was implanted with an atrial lead Biotronik SX 53-JBP positioned in the right atrial appendage and a ventricular lead Biotronik SX 60-BP positioned in the right ventricular apex. A few months after generator change the patient underwent a diagnostic process due to heart palpitations and stabbing pain in the chest. The chest pain occurred during body movements and deep breathing. In electrocardiographic Holter monitoring the sensing disturbances in the ventricular channel were detected. During pacemaker interrogation the electrical parameters of both leads were normal except for an increased number of short $\mathrm{V}-\mathrm{V}$ intervals. The patient was qualified to transvenous ventricular lead extraction and implantation of a new ventricular lead. In the meantime the patient underwent a computed tomography scan in search of coronary heart disease, and it was found that the ventricular lead was perforating the intraventricular septum on the level of the apical septal segment. The length of the lead in the left ventricle amounted to 7-9 mm (Fig. 1A). The displacement of the lead was suspected also in a chest X-ray of the current location of the lead (Fig. 1B). In transthoracic and transoesophageal echocardiography the thrombus on the lead tip and left-to-right shunt through the septum along the lead were ruled out (Fig. 1C). The decision to extract the ventricular lead transvenously with mechanical systems with surgical backup and transoesophageal echocardiography monitoring was upheld. The procedure was a complete success. There was no residual left-to-right shunt after the extraction of the lead. Subsequently the new ventricular lead was implanted (Fig. 1D). The presented case is an example of a rare and dangerous complication of permanent pacing. The existence of a short portion of ventricular lead inside the left ventricle posed a risk of thrombus formation and peripheral embolisation, of which the most dangerous is stroke. The late perforation of intraventricular septum by a passive fixation lead has not been reported in English-language literature yet. The probable cause of the distant (in time) perforation was the application of excessive force on the tip of the lead during implantation, which was then aggravated by the ingrown lead into the tricuspid valve region. Transvenous extraction of the lead displaced into the left ventricle requires surgical intervention according to the current Heart Rhythm Society (HRS) expert consensus. In this case a less invasive approach was successfully used. However, close attention was directed toward identification and prevention of potential perioperative complications such as left-to-right shunt after lead extraction and arterial embolisation. Furthermore, the procedure was conducted with surgical backup and continuous intraoperative transoesophageal monitoring.
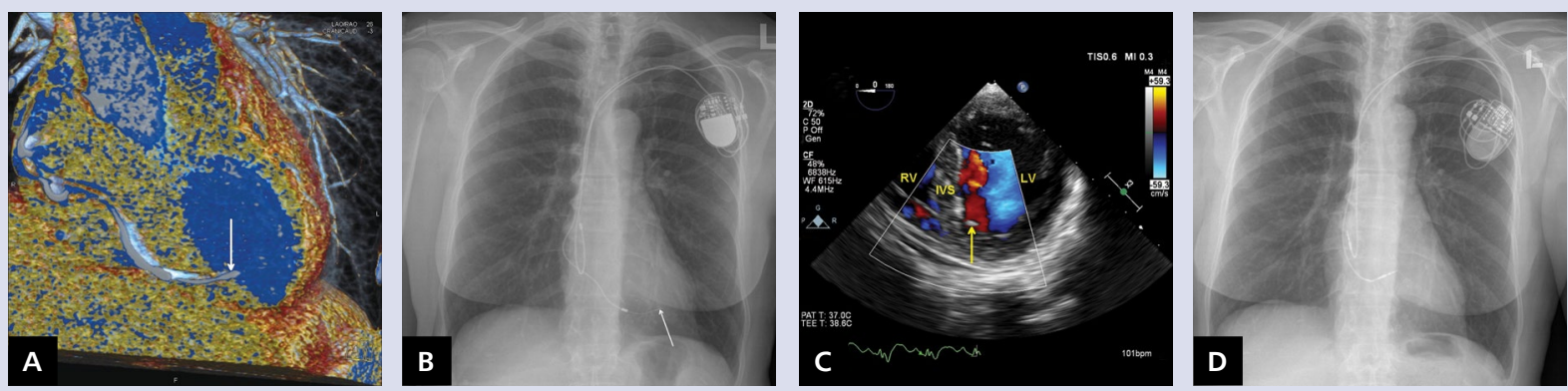

Figure 1. A. Computed tomography scan, arrow indicates the tip of ventricular lead in the left ventricle; B. Chest X-ray before transvenous lead extraction procedure, arrow indicates displaced tip of the ventricular lead; $\mathbf{C}$. Transoesophageal echocardiography with colour Doppler, arrow indicates right ventricular lead in left ventricle (LV); RV — right ventricle; IVS - intraventricular septum; $\mathbf{D}$. Chest X-ray after implantation of new DDD pacemaker

Address for correspondence:

Krzysztof Boczar, MD, Department of Electrocardiology, John Paul II Hospital in Krakow, ul. Prądnicka 80, 31-202 Kraków, Poland, e-mail: krzysiek.boczar@gmail.com Conflict of interest: none declared

Kardiologia Polska Copyright (c) Polskie Towarzystwo Kardiologiczne 2017 